\title{
The Resistance Spot Weldability of a Stainless Steel/Aluminium/Low Carbon Steel 3-Ply Clad Sheet
}

\author{
Siva Prasad Murugan*, Muralimohan Cheepu**, Vijeesh Vijayan*, \\ Changwook $\mathrm{Ji}^{* * *}$, and Yeong-Do Park*, \\ *Department of Advanced Materials Engineering, Dong-Eui University, Busan, 47340, Korea \\ **Department of Mechatronics Engineering, Kyungsung University, Busan, 48434, Korea \\ ***Advanced Forming Process R\&d Group, KITECH, Ulsan, 44413, Korea
}

†Corresponding author : ypark@deu.ac.kr

(Received December 21, 2017 ; Revised January 15, 2018 ; Accepted January 22, 2018)

\begin{abstract}
The present paper is aimed at investigating the resistance spot weldability of a 3-ply clad sheet comprised of stainless steel (SS), aluminium (Al) and low carbon steel (LCS). The weldability was assessed with the help of the weldable current range (WCR), the current range between the minimum current required to produce $4 \sqrt{ } \mathrm{t}$ nugget diameter and a maximum current at which expulsion occurs. However, electrode-sheet sticking was found as the limiting factor instead of expulsion. It was observed that the introduction of aluminium to the SS/LCS clad increased the weld current range by shifting the expulsion to higher current, but resulted in melting of the electrode and subsequent electrode-sheet sticking.
\end{abstract}

Key Words : Weldability, Aluminium, Intermetallic compound layer, Electrode-sheet sticking, Liquid $\mathrm{Cu}$ penetration.

\section{Introduction}

The demand for multifunctional materials for optimized performance and cost is constantly increasing for the past few years. A feasible way to achieve multifunctionality is to integrate materials of different properties $^{1-3)}$. Amongst several methods of producing multifunctionality sheets, a direct cladding of two or more materials is effective and economical ${ }^{3-5}$. The bimetallic cladding of stainless steel and aluminium or low carbon steels resulted in bilayer sheets of great interest to engineering applications ${ }^{6}$. The stainless steel (SS) and low carbon steel (LCS) clad sheets are of great interest to a variety of manufacturing industries such as shipbuilding, reactor vessels, chemical tanks and construction sectors due to its excellent mechanical and corrosion resistance properties ${ }^{7)}$. The SS in the clad sheet imparts corrosion resistance towards gaseous and aqueous medium and low carbon steel offers excellent weldability and strength at lower cost over SS. In the recent past, aluminium inserted SS/LCS three layer clad sheet has been developed with improved multifunctionality and reduced weight for futuristic automobile applications ${ }^{2,4)}$. The use of such a clad in the automobile industry as muffler material also widens its applications. A sound bonding between the 3-ply component layers was obtained by optimizing the rolling process parameters. However, the three-layered clad sheet and mechanism of bond formation is least understood, and its weldability is yet to be investigated.

Among the commonly used welding processes, resistance spot welding (RSW) is extensively used for sheet metal joining, particularly in the automobile industry for body-in-white assemblies. Fast and fully automated RSW process is free from filler materials as the joining is achieved using the heat generated due to the resistance to electric current flow ${ }^{8-10)}$. However, the use of such a fusion welding process on three layered clad sheets would be a challenging task as there are large discrepancies in chemical, mechanical and thermal properties of the component materials. Even though, sandwiching of aluminum between the low carbon steel and stainless steel layers would result in significant 
weight reduction, the formation of a Fe-Al intermetallic compound layer at the interface during the welding process is a major factor of concern ${ }^{11-14)}$. A few studies are available aimed at controlling the generation of $\mathrm{Fe}-\mathrm{Al}$ intermetallic reaction layer by different techniques such as welding with a transition material (Fe/Al clad sheet) ${ }^{15)}$, optimizing the welding process parameters $^{13)}$ and introducing an interlayer (Al-Mg alloy) ${ }^{16)}$. Sun et al. ${ }^{15)}$ introduced a new technique to obtain better resistance spot weldability between $\mathrm{Al}$ and steel using the $\mathrm{Fe} / \mathrm{Al}$ clad sheet as a transition material. During RSW of steel and aluminum, a transition material was placed in between steel and aluminum to suppress the reaction between aluminum and steel. Similarly, the unbalanced heat generation and uneven melting during dissimilar RSW of aluminum and steel have been extensively studied in the past. In the process, Qui et al. ${ }^{12)}$ successfully joined aluminum alloy to steel and stainless steel using resistance spot welding with a cover plate. However, the resistance spot welding of similar/dissimilar sheets of $\mathrm{Al} /$ steel or $\mathrm{Al} /$ stainless steel clad is an unexplored area. Moreover, the development of three layered clad sheet necessitates the study of its resistance spot weldability in order to widen its applications.

The present study is aimed at studying the feasibility of resistance spot weldability of an aluminium inserted stainless steel/low carbon steel 3-ply clad sheet. In detail, the paper attempts to explore the following: (1) weldability and the mechanism of weld nugget formation, (2) microstructural evolution of clad components during RSW process (3) defects if any. A comprehensive study on the mechanical properties and fracture behavior of the same clad material can be found elsewhere $^{17)}$.

\section{Experimental}

A 3-ply hot rolled clad sheet comprising of austenitic stainless steel- AISI $304(0.25 \mathrm{~mm})$, commercially pure aluminium- AA $1050(0.25 \mathrm{~mm})$ and galvanized low carbon steel- AISI $1008(0.7 \mathrm{~mm})$ of $1.2 \mathrm{~mm}$ overall thickness was used for the investigation. Resistance spot welding of the clad sheets with carbon steel/ carbon steel interface was carried out using a robot operated servo-controlled C-type weld gun integrated with medium frequency direct current (MFDC) power source. $\mathrm{A} \mathrm{Cu}-\mathrm{Cr}$ dome-type electrode of $6 \mathrm{~mm}$ face diameter was used for the study. The schematic diagram of the sample arrangement for the welding and cross-sectional scanning electron microscopy (SEM) image of the clad sheet base metal with energy-dispersive X-ray spectroscopy (EDS) analysis are shown in Fig. 1. The spot welds on clad sheets were obtained with various weld currents ranging from $8 \mathrm{kA}$ to $15 \mathrm{kA}$ at an interval of 1 $\mathrm{kA}$. Table 1 shows the welding parameters used for the present study. The metallographic analysis of the weldments was carried out using an optical microscopy after standard metallographic preparations and chemical

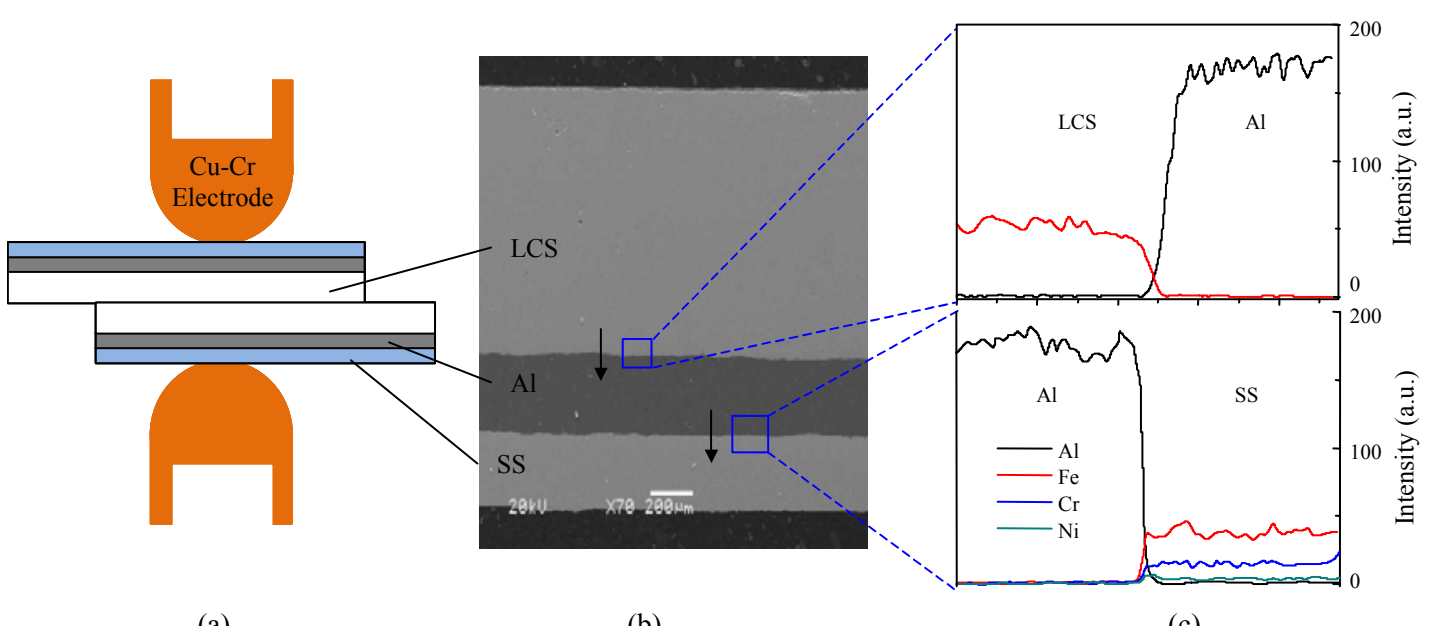

(a)

(b)

(c)

Fig. 1 (a) Schematic sketch of the RSW of clad sheets (b) SEM image and (c) EDS analysis of the parent clad sheet

Table 1 Welding parameters used for the study

\begin{tabular}{|c|c|c|c|c|c|}
\hline $\begin{array}{c}\text { Squeeze time (cy) } \\
(1 \mathrm{cy}=16.7 \mathrm{~ms})\end{array}$ & $\begin{array}{c}\text { Weld time } \\
(\mathrm{cy})\end{array}$ & $\begin{array}{c}\text { Weld current } \\
(\mathrm{kA})\end{array}$ & $\begin{array}{c}\text { Holding time } \\
(\mathrm{cy})\end{array}$ & $\begin{array}{c}\text { Electrode force } \\
(\mathrm{kN})\end{array}$ & $\begin{array}{c}\text { Electrode diameter } \\
(\mathrm{mm})\end{array}$ \\
\hline 60 & 18 & $8-15$ & 20 & 3 & 6 \\
\hline
\end{tabular}


etching. The SEM with EDS attachment was used to identify and characterize the intermetallic formed at the clad interfaces.

To understand and determine the temperature history during RSW of clad sheet, a commercial software 'SORPAS' was used ${ }^{18,19)}$. The required geometry of the clad sheet was designed in the graphic user interface of the SORPAS, assigning different material properties from the predefined SORPAS database. All the input parameters such as geometry and the properties of workpiece and electrode, machine characteristics and weld parameters were kept as in real welding experiments.

\section{Results and Discussion}

\subsection{Weldability and nugget formation}

Amongst several ways to define the resistance spot weldability, the weldable current range (WCR) is the most common and effective criterion for weldability as- sessment $^{17,20-22)}$. WCR is defined as the current range between the minimum current required to obtain a nugget diameter of $4 \sqrt{t}$, where ' $t$ ' is the sheet thickness, and a maximum current at which expulsion occurs ${ }^{19)}$. However, electrode-sheet sticking (ESS) is observed before the occurrence of expulsion. Thus, ESS is considered as the upper limit in the calculation of WCR instead of expulsion, limiting the WCR to the ESS current. Subsequently, WCR is redefined as the allowable weldable current range between the current required to obtain the minimum nugget diameter and the current at which ESS starts to occur. Fig. 2a shows the WCR of the clad sheet used in the present investigation. The $\mathrm{D}_{\min }$ in the figure represents the minimum nugget diameter, which is considered as $4 \sqrt{\mathrm{t}}(4.56 \mathrm{~mm})$ and corresponding $I_{\min }(12 \mathrm{kA})$ is the minimum current required to obtain acceptable nugget size. Furthermore, the nugget size increases with the increase in current until the maximum possible current is restricted by the sticking of the electrode to the sheet. The $\mathrm{I}_{\mathrm{ESS}}$ in Fig. 2a

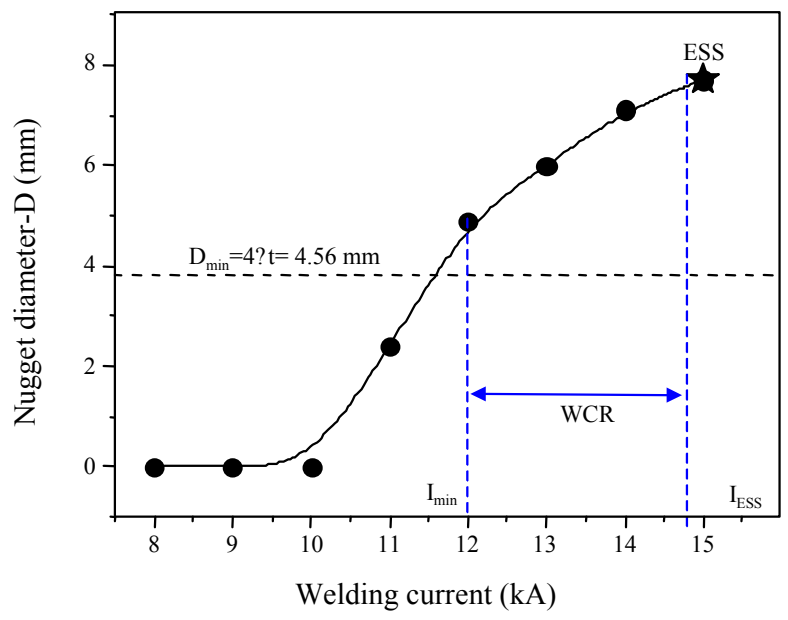

(a)

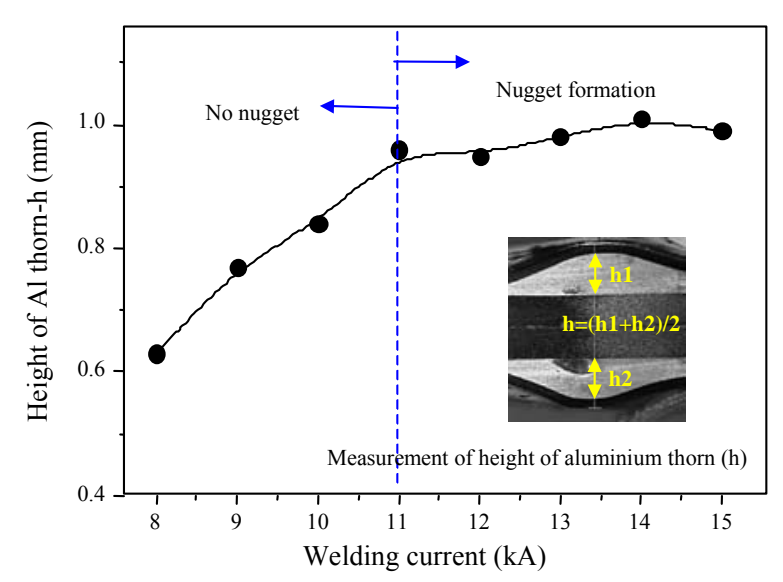

(c)

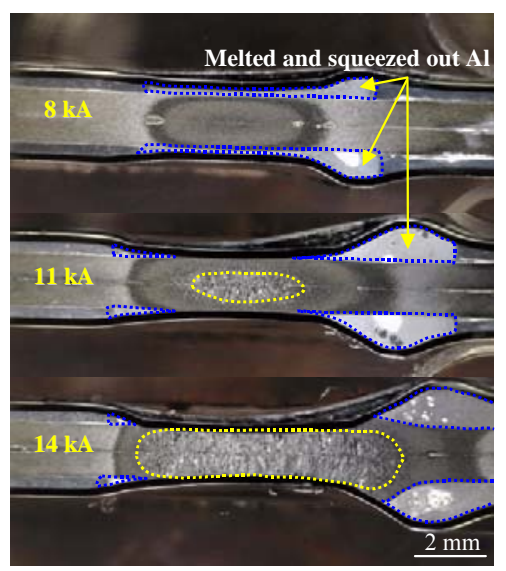

(b)

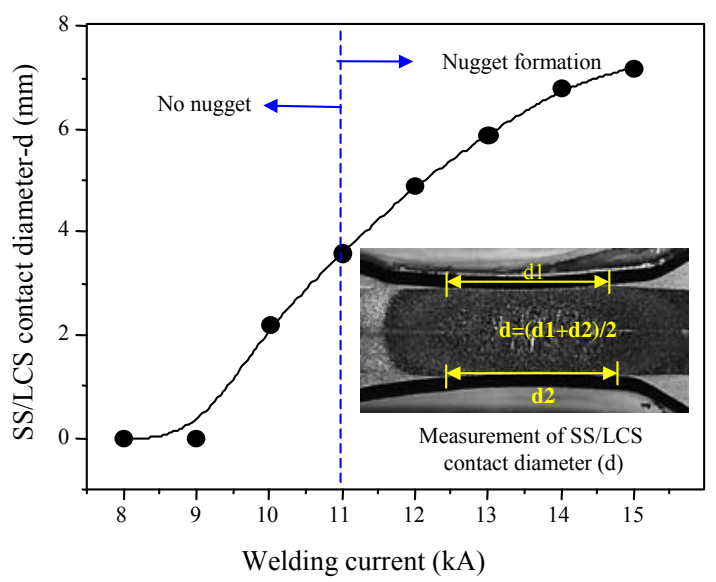

(d)

Fig. 2 (a) Nugget diameter with varying weld current and weldable current range (WCR) (b) optical images of cross section of nuggets at selected weld currents (c) height of the aluminium thorn with varying weld current (d) SS/LCS contact diameter with varying weld current 
corresponds to the current at ESS and WCR is calculated as the range between sticking current and minimum current $\left(\mathrm{WCR}=\mathrm{I}_{\mathrm{ESS}}-\mathrm{I}_{\min }\right.$ ). The $\mathrm{WCR}$ for the resistance spot welding of the clad sheets used in the present investigation was found to be $3 \mathrm{kA}$, with $\mathrm{I}_{\min }$ of $12 \mathrm{kA}$ and I ESS of $15 \mathrm{kA}$. Even though, the current values below $\mathrm{I}_{\min }(<12 \mathrm{kA})$ resulted in the melting and nugget formation, the nuggets were far below the required size. Similarly, the currents above $\mathrm{I}_{\mathrm{ESS}}(>15 \mathrm{kA})$ resulted in further melting and sticking of the electrode.

The micrographs of the nugget formed at selected weld currents are shown in Fig. 2b. A regular shaped large nugget with a diameter of $7.1 \mathrm{~mm}$ is observed at a weld current of $14 \mathrm{kA}$. The nugget formation begins at LCS/LCS interface and a small portion of SS melts to merge with the growing nugget. At low welding currents, such as $8 \mathrm{kA}$ (Fig. 2b) could only melt and partially squeeze out the aluminium from the core of the clad. The heat produced is not sufficient to melt the sheet to sheet interface and initiate nugget formation as part of the energy is consumed for melting and squeezing out of aluminium. On the other hand, high currents from $11 \mathrm{kA}$ to $14 \mathrm{kA}$ produce enough heat energy for squeezing out of aluminium and nugget formation at the LCS/LCS interface. Thus, it indicates that the melting and subsequent squeezing out of aluminium from core plays a key role in the nugget formation. For better understanding, the squeezed-out aluminium is quantified by measuring the size of the aluminium "thorn" formed (indicated by $h$ in Fig. 2b) and the SS/LCS contact diameter (indicated by d). Fig. 2c and $2 \mathrm{~d}$ show the variation in thorn and contact diameter with weld currents. The size of the thorn and the contact diameter increase with the current, thereby increasing the interaction of LCS and SS in the clad sheet. The squeeze out of aluminium to one side of the nugget (i.e., the formation of thorn) is merely a function of practical electrode misalignment. As observed in Fig. 2c, the squeeze out of the aluminium occurs at all currents, however, the quantity of the squeeze out increases with current, reaching a saturation level at $11 \mathrm{kA}$. The height of thorn remains nearly constant for further increase in current. At low currents, $8 \mathrm{kA}$ to $10 \mathrm{kA}$, partial melting and squeeze out of aluminium occur, hindering the melting or nugget formation. It also indicates that the generated heat has not yet reached sufficient level to melt the steel at the faying interface. As the current increases to $11 \mathrm{kA}$, a large amount of aluminium is melted and squeezed out due to the combined effect of heat and pressure, consequently, the interface temperature rises to make a small weld nugget. Furthermore, at higher weld currents $(>11 \mathrm{kA})$ large nuggets are formed due to complete squeeze out of aluminium from the weld zone and the welding occurs between low carbon steel and stainless steel. It can be summarized that there is no nugget formation below $11 \mathrm{kA}$, and nugget formation starts to oc-

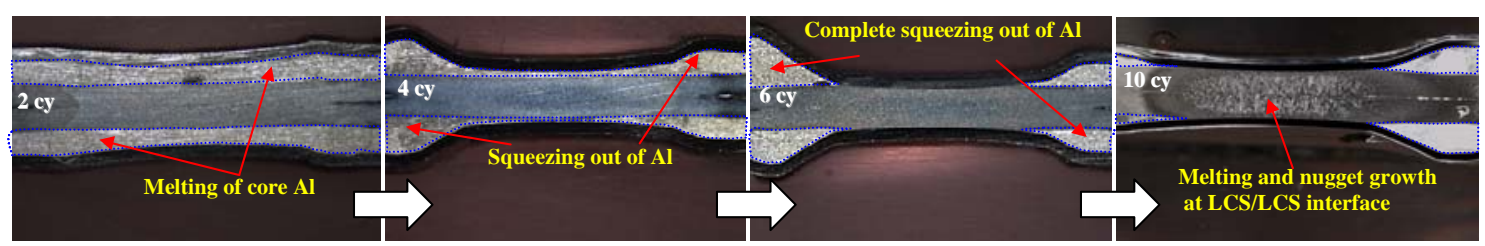

(a)

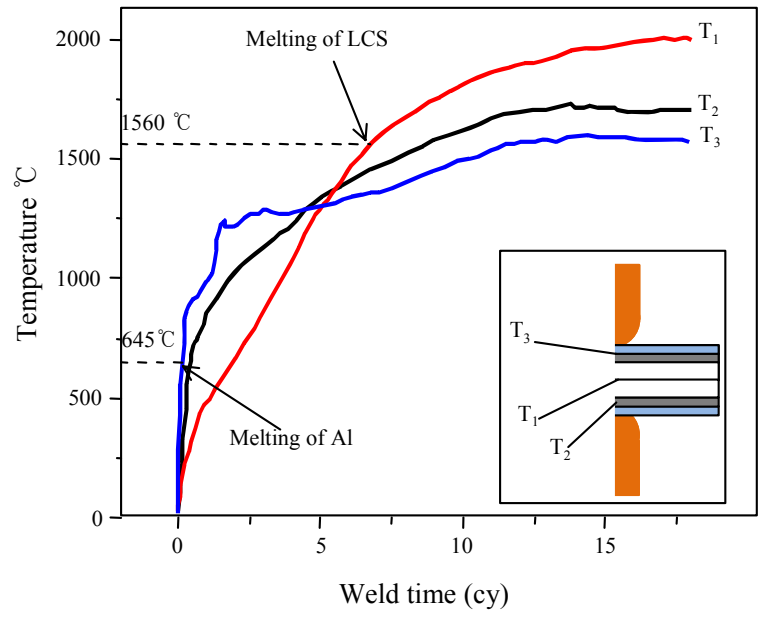

(b)

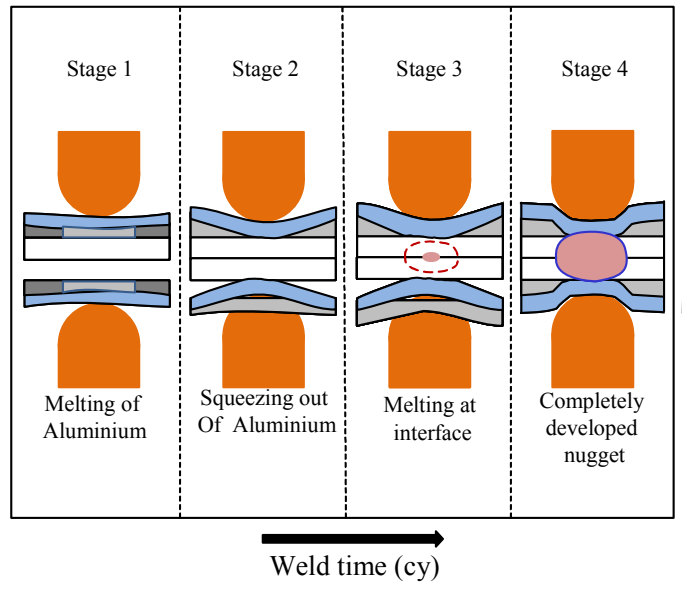

(c)

Fig. 3 (a) Cross sectional macro images at different weld time for a weld current of $14 \mathrm{kA}$ (b) temperature profile of different interfaces during welding obtained from SORPAS (c) Schematic illustration showing various stages in the nugget formation during RSW of 3 ply sheet clad 
cur at $11 \mathrm{kA}$ as a result of aluminium squeeze out and is depicted clearly in Fig. 2c and 2d.

Various stages of nugget formation during RSW of aluminum inserted clad sheet is explained in Fig. 3. The cross-sectional macro images of the clad sheet welds at different weld time for a weld current of $14 \mathrm{kA}$ is shown in Fig. 3a. The melting of the Al layer begins at the initial stage ( 2 cy) of welding, followed by squeezing out of molten $\mathrm{Al}$ at later cycles ( $2 \mathrm{cy}$ to $6 \mathrm{cy}$ ) due to the compressive force from the electrode. However, no melting or nugget formation occur at LCS/LCS interface during the melting and squeezing out of Al (1-6 cy). Melting at the interface starts only after the completion of squeezing out of the aluminum from the core. Thereafter, the melted interface and the nugget grows further with the passage of weld current (12 cy). Fig. 3b shows the temperature profile at various locations of the clad sheet during RSW with a current of $14 \mathrm{kA}$. The temperature at LCS/LCS interface is $\mathrm{T}_{1}$, at the core aluminium is $T_{2}$ and at aluminium/stainless steel interface is $T_{3}$. This simulated temperature history of each clad component during welding completely agrees with the nugget formation stages explained using Fig. 3a. Fig. 3b also shows an early melting of the $\mathrm{Al}(\sim 1 \mathrm{cy})$ and a de- layed melting at LCS/LCS interface ( $\sim 7 \mathrm{cy})$. The observations from both the cross-sectional images (Fig. $3 a$ ) and the temperature profile (Fig. 3b) can be used to elucidate the stages of nugget formation in the RSW of clad sheet (Fig. 3c). The stages of the nugget formation are: melting of core aluminium (stage 1); squeezing-out of molten aluminium (stage 2); melting initiation and growth in LCS/LCS interface (stage 3); melting of stainless steel and completion of nugget formation (stage 4 ).

\subsection{Microstructure}

Fig. 4 shows the microstructure of the weld nugget and SS/LCS interface obtained using a current of 14 $\mathrm{kA}$. The microstructure mainly consists of columnar grains growing in the direction of electrode due to the large temperature gradient in the fusion zone of low carbon steel. The $\mathrm{Cu}$ electrode along with flowing coolant increase the heat transfer rate in its direction and cause thermal gradient in the melt. The microstructure also indicates that the nugget contained of LCS and the melting is rather between the LCS/LCS of the clad than among all constituents. Though the clad consisted $\mathrm{Al}$ and $\mathrm{SS}$, their participation in the nugget formation is

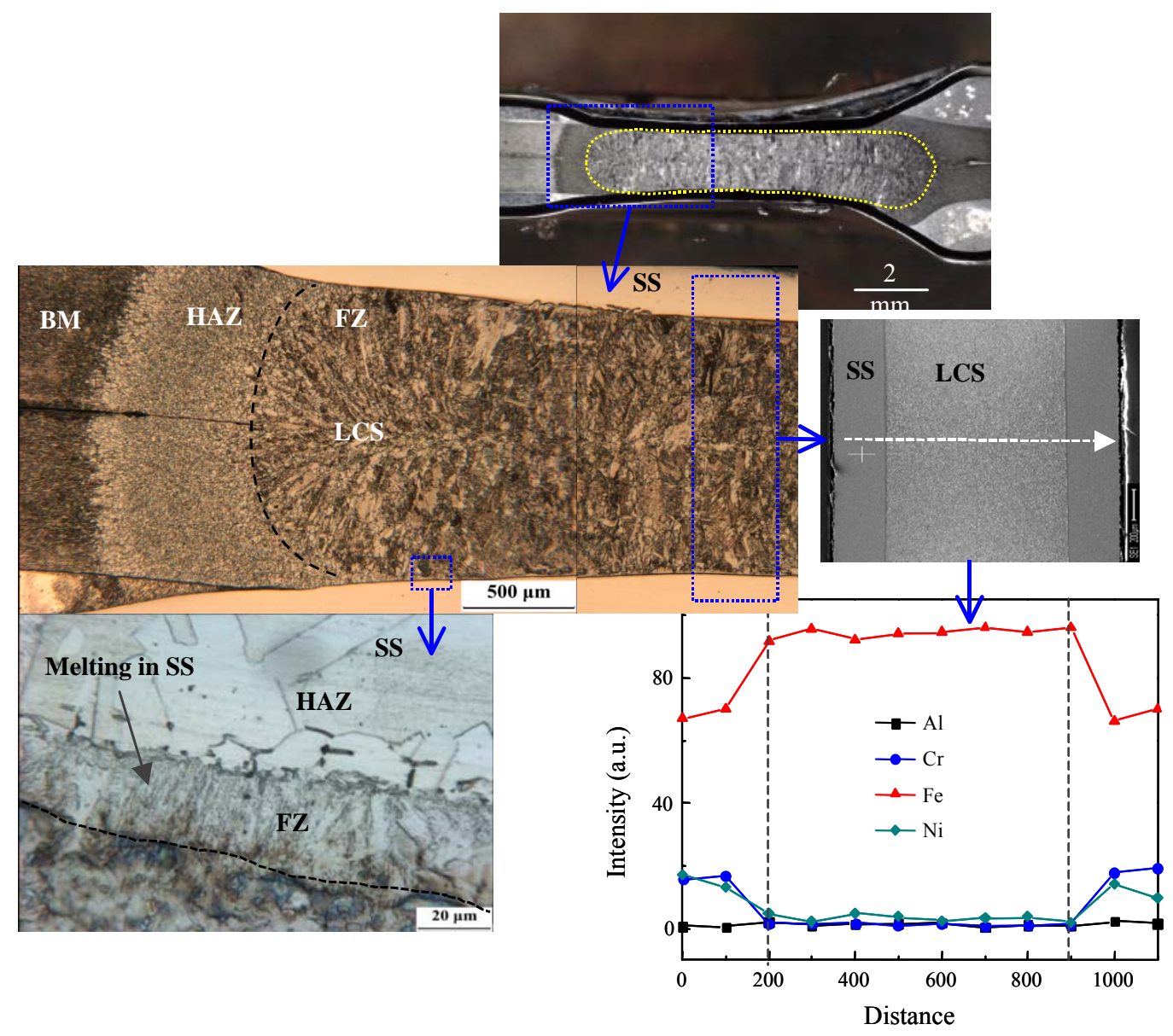

Fig. 4 Optical micrographs and SEM-EDS line analysis of the nugget welded at $14 \mathrm{kA}$ 

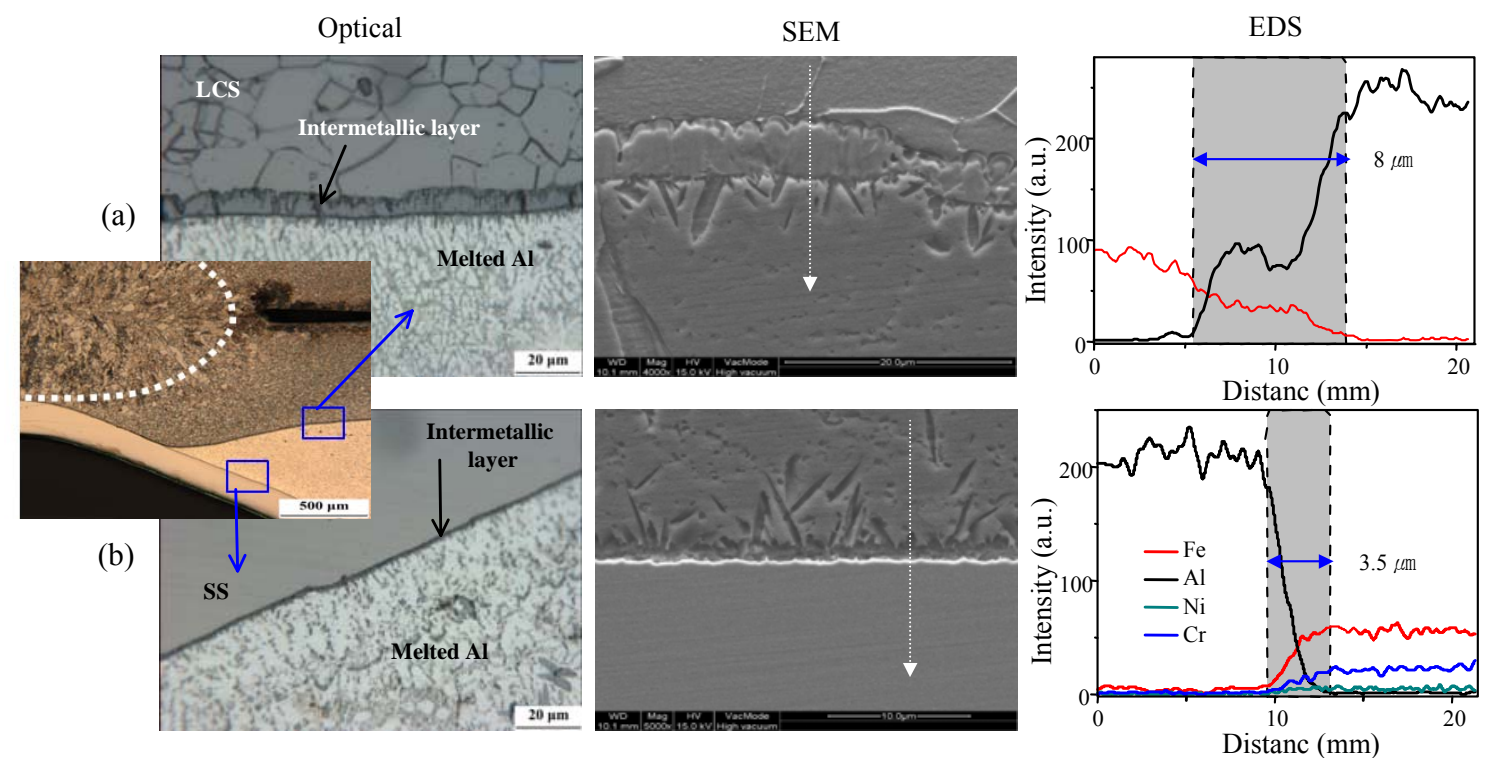

Fig. 5 Optical microscopy, SEM and EDS line analysis of the intermetallic reaction layer (a) LCS/Al interface (b) Al/SS interface

negligible due to several reasons explained in earlier sections. However, a small portion of the stainless steel melted along with LCS at higher current to take part in the nugget formation. SEM-EDS analysis shown in Fig. 4 , reveal that the aluminium or aluminium intermetallic are absent in the nugget or HAZ (in the thickness direction). However, the squeezed-out aluminium results in the formation of intermetallic compound layer away from the nugget as shown in Fig. 5. The squeezed-out aluminium reacts with both LCS and SS interfaces to form the intermetallic compound layer. The EDS analysis reveals that the intermetallic compound layer predominantly consists of $\mathrm{Fe}$ and $\mathrm{Al}$ with some traces of $\mathrm{Ni}$ and $\mathrm{Cr}$. The reaction layers with intermetallic compounds, as shown in Fig. 5, are formed in the LCS/Al and SS/Al interface due to the interfacial reaction between molten aluminium and solid iron ${ }^{23}$. It is clear from the figure that the reaction layer formed in LCS/Al interface is thicker than that of SS/Al interface. This difference in thickness is attributed to the temperature at which the reaction between aluminium and iron occurs. The temperature at $\mathrm{LCS} / \mathrm{Al}$ interface is higher than that of SS/Al interface. Kobayashi et al reported that the thickness of the interfacial reaction layer between aluminium and iron increased with increasing the temperature at which the reaction takes place ${ }^{24)}$. The high magnification SEM images reveal the two-layered structure of reaction layers, a tongue like layer towards iron side and a fine needle like layer towards Al side. According to the Fe-Al binary phase diagram, the intermetallic compounds present in the interfacial reaction layer could be $\mathrm{Fe}_{2} \mathrm{Al}_{5}, \mathrm{FeAl}_{3}, \mathrm{FeAl}_{2}$ or FeAl.

\subsection{Electrode-sheet sticking (ESS)}

Electrode-sheet sticking is characterized by the bonding of electrode to the sheet surface which occurs when excessive heat is generated at the electrode-sheet interface. It is strictly an undesirable phenomenon in resistance spot welding process similar to expulsion as it severely affects the weldable current range as described in section 3.1. The present study shows a sticking phenomenon at a current of $15 \mathrm{kA}$. To understand the reason for sticking and to study its effect on welding, RSW of clad sheet is simulated in SORPAS. The temperature history at the electrode and sheet interface during welding with $15 \mathrm{kA}$ is shown in Fig. 6. The profile indicates that the temperature at the electrode sheet interface increases with weld time and goes well beyond the melting temperature of copper. Thus, the copper electrode

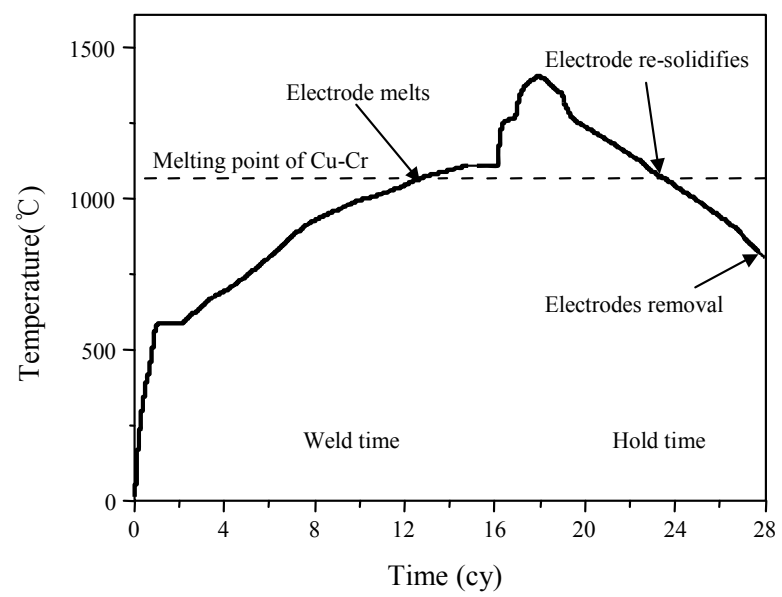

Fig. 6 The temperature at the electrode sheet interface as function of weld time 
melts during the weld time and solidifies before the completion of hold time, as indicated in Fig. 6. Since the liquid copper solidifies before the removal of the electrode from the clad sheet, the electrode sticks to the sheet surface. Generally, the temperature at the electrode-sheet interface does not reach up to the melting point of copper as the generated heat is quickly removed by the electrode coolant. However, transfer of high weld currents such as $15 \mathrm{kA}$ to clad sheet induces a large amount of heat into the material at a faster rate without any expulsion. The expulsion in the two-sheet similar or dissimilar combination welding has been reported to occur before sticking. The expulsion current during welding of carbon steel/carbon steel, stainless steel/stainless steel or stainless steel/ carbon steel has a maximum value of $13 \mathrm{kA}^{25,26)}$. But, the selected clad material does not show any expulsion even at a weld current of $15 \mathrm{kA}$ and could be possibly due to the presence of aluminium in the core of the clad sheet. It can be inferred that the aluminium present in the core dissipates the heat generated during the initial stages of welding, raising the weldable current above the normal current required for mild steel or stainless steel. However, the squeezing out of molten aluminium results in the formation of a bimetallic strip of carbon steel and stainless steel, exposing the carbon steel at the sheet to sheet interface and stainless steel at the sheet to electrode interface. The relatively high bulk resistance and con- tact resistance of stainless steel cause an excessive heat generation at the electrode/sheet interface.

Since ESS was observed well before the occurrence of expulsion, it is considered as the upper limit in the calculation of weldable current range instead of weld metal expulsion, reducing the weldable current range of the clad sheet.

\subsection{Liquid Cu penetration}

The liquid $\mathrm{Cu}$ produced during ESS penetrates deep into the clad sheet through the austenitic stainless steel layer and solidifies along the weld metal. The entire phenomena of melting, penetration and solidification of $\mathrm{Cu}$ during ESS are explained schematically in Fig. 7a. The optical microstructure of different locations marked as b1, b2, b3, b4, b5 and b6 in the schematic diagram are magnified in Fig. $7 \mathrm{~b}$. The base microstructure of the $\mathrm{Cu}$ electrode away from the tip, shown in b1 of Fig. 7b, is characterized by the presence of elongated grains owing to the cold drawing manufacturing route present uniformly through the entire section. It is evident from the b2 of Fig. 7b that a significant amount of electrode melted during ESS cause brazing of electrode to the clad sheet. The melted region with a dendritic solidification structure and a heat affected $\mathrm{Cu}$ zone, the region that does not melt during welding observed in the

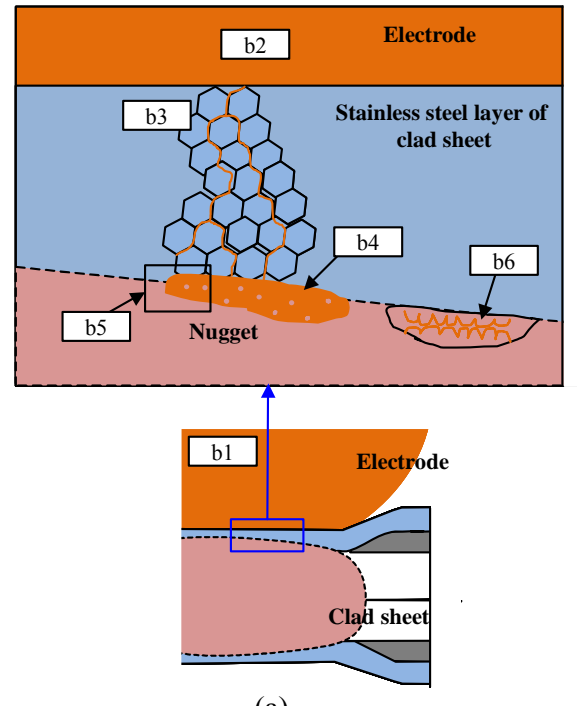

(a)

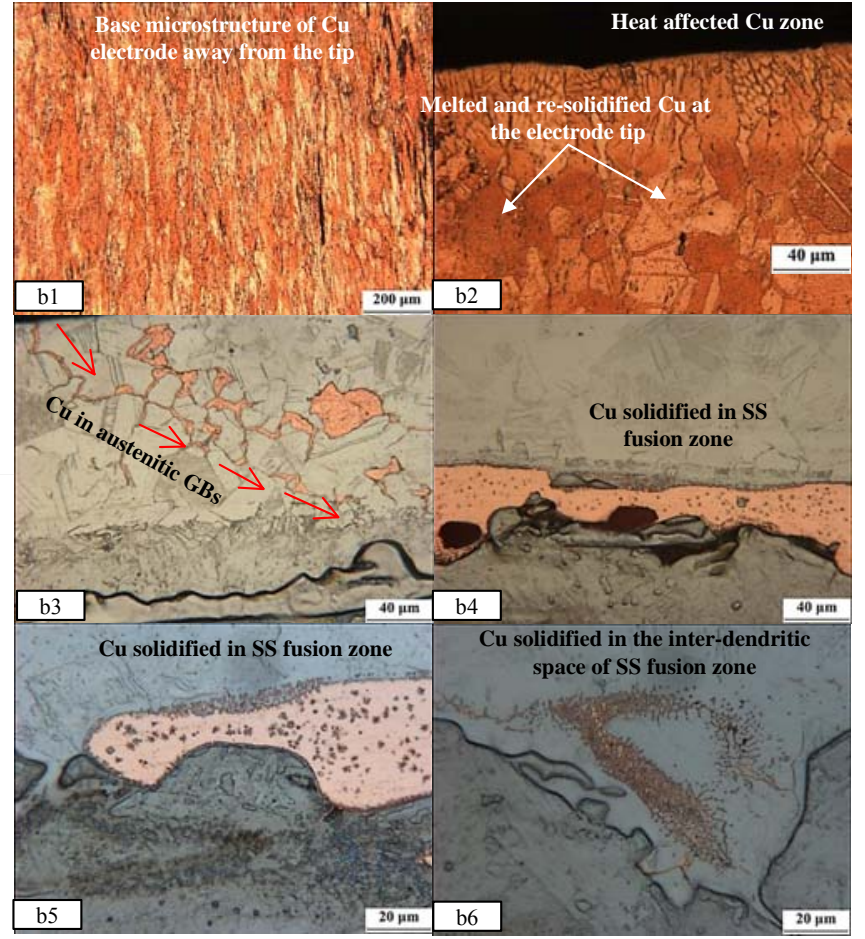

(b)

Fig. 7 (a) schematic sketch illustrating the liquid penetration through stainless steel grain boundaries (b) optical micrographs of electrode and clad sheet with penetrated copper 
figure is the evidence for liquification of the electrode tip. The change in the grain structure in HAZ zone of $\mathrm{Cu}$ electrode caused due to complete recovery, recrystallization and growth would cause extreme softening of welding electrode affecting the life of the electrode.

The liquid copper penetrates the microstructure through austenitic grain boundaries, as shown in Fig. 7 (b3). The capillary action of $\mathrm{Cu}$ reduces the surface free energy of the austenitic grain boundaries ${ }^{27)}$ and acts as the driving force for the penetration of $\mathrm{Cu}$. The penetrated liquid copper enters the nugget and solidifies in the fusion zone of stainless-steel as shown in (b4). Two kinds of solidification structures are observed from the micro images: Fe globules and dendritic fragments embedded in the $\mathrm{Cu}$ matrix (b5) and inter-dendritic $\mathrm{Cu}$ phase in the Fe matrix (b6), as reported in reference ${ }^{28)}$. The mechanism of such variation in $\mathrm{Cu}$ structure can be explained with $\mathrm{Fe}-\mathrm{Cu}$ binary system reported elsewhere ${ }^{29}$. During the cooling period, the mixture of liquid metal enters a metastable liquid miscibility gap and separates into two different liquids such as $\mathrm{Fe}$-rich liquid and a $\mathrm{Cu}$-rich liquid. Both liquids solidify simultaneously, one in the form of spheres, dendrites or interdendritic phase and the other as the matrix, depending on the chemical composition. If the liquid contains more than $50 \mathrm{wt} \%$ $\mathrm{Cu}$, dendrites and globules originate from Fe-rich liquid and the matrix originates from $\mathrm{Cu}$-rich liquid, and forms a microstructure with $\mathrm{Fe}$ globules and dendritic fragments embedded in the $\mathrm{Cu}$ matrix (b5). On the other hand, if the liquid contains less than $50 \mathrm{wt} \% \mathrm{Cu}$, interdendritic $\mathrm{Cu}$ phase originates from $\mathrm{Cu}$-rich liquid and dendritic matrix originates from Fe-rich liquid, which results in a microstructure of inter-dendritic $\mathrm{Cu}$ phase in the Fe matrix (b6).

\section{Conclusions}

In the present paper, the resistance spot weldability of the 3-ply clad of stainless steel/aluminium/low carbon steel (SS/Al/LCS) was investigated by assessing weldable current range. Based on the results and discussion, the following conclusions were drawn.

1) The core aluminium played a major role in the nugget formation. The initiation of melting and growth of nugget starts only after the complete squeeze out of aluminium.

2) A reasonable weldable current range of $3 \mathrm{kA}$ ensures a remarkable weldability of clad material. However, the upper limit of the applied current was restricted to $15 \mathrm{kA}$ due to sticking of the electrode to the sheet.

3) $\mathrm{Fe}-\mathrm{Al}$ intermetallic compound layer was formed in the steel/Al and SS/Al interfaces outside the weld nug- get as a result of interfacial reaction between solid iron and liquid aluminium.

4) The insertion of aluminum into the SS/LCS clad sheet shifted the expulsion to a higher current by conducting more heat away from the interface. However, the beneficial effect was upset by the temperature rise at the electrode sheet interface and the subsequent electrode-sheet sticking and liquid $\mathrm{Cu}$ penetration into the material.

\section{Funding}

This work was carried out under the project "Multi-materials integration" (project number:10063579) supported by Ministry of Trade, Industry and Energy, Republic of Korea.

ORCID: Siva Prasad Murugan: https://orcid.org/0000-0003-1583-772X ORCID: Muralimohan Cheepu: https://orcid.org/0000-0002-8282-1237 ORCID: Vijeesh Vijayan: https://orcid.org/0000-0003-4023-033X ORCID: Changwook Ji: https://orcid.org/0000-0002-5158-5243 ORCID: Yeong-Do Park: https://orcid.org/0000-0002-0165-4749

\section{References}

1. J. E. Lee, D. H. Bae, W. S. Chung, K. H. Kim, J. H. Lee and Y. R. Cho, Effects of annealing on the mechanical and interface properties of stainless steel/aluminum/ copper clad-metal sheets, Journal of Materials Processing Technology, 187-188 (2007), 546-549 https://doi.org/10.1016/j.jmatprotec.2006.11.121

2. T. Okui, K. Yoshida and Y. Yonemitsu, Development of Metal Clad Sheets and Strips, Nippon Steel and Sumitomo Metal Technical Report, 106 (2014), 103-107

3. T. Mori and S. Kurimoto, Press-formability of stainless steel and aluminum clad sheet, Journal of Materials Processing Technology, 56 (1996), 242-253 https://doi.org/10.1016/0924-0136(95)01838-7

4. W. Deqing, S. Ziyuan and Q. Ruobin, Cladding of stainless steel on aluminum and carbon steel by interlayer diffusion bonding, Scripta Materialia, 56 (2007), 369372 https://doi.org/10.1016/j.scriptamat.2006.11.003

5. K. Y. Rhee, W. Y. Han, H. J. Park and S. S. Kim, Fabrication of aluminum/copper clad composite using hot hydrostatic extrusion process and its material characteristics, Materials Science and Engineering A, 384 (2004), 70-76 https://doi.org/10.1016/j.msea.2004.05.051

6. H. R. Akramifard, H. Mirzadeh and M. H. Parsa, Cladding of aluminum on AISI 304L stainless steel by cold roll bonding, Mechanism, microstructure, and mechanical properties, Materials Science and Engineering A, 613 (2014), 232-239 https://doi.org/10.1016/j.msea.2014.06.109

7. S. Missori, F. Murdolo and A. Sili, Single-pass laser beam welding of clad steel plate, Welding Journal, 83 
(2004), 65-71

8. H. Zhang and J. Senkara, Resistance Welding, Fundamentals and Applications, CRC Press Taylor \& Francis Group, New York (2012)

9. M. Pouranvari and P. Marashi, Critical review of automotive steels spot welding, process, structure and properties, Science and Technology of Welding and Joining, 18 (2013), 361-403 https://doi.org/10.1179/1362171813Y.0000000120

10. M. Tumuluru, Welding and Joining of Advanced High Strength Steels, (2015), 55-70 https://doi.org/10.1016/B978-0-85709-436-0.00004-7

11. T. Tanaka, T. Morishige and T. Hirata, Comprehensive analysis of joint strength for dissimilar friction stir welds of mild steel to aluminum alloys, Scripta Materialia, 61 (2009), 756-759 https://doi.org/10.1016/j.scriptamat.2009.06.022

12. R. Qiu, C. Iwamoto and S. Satonaka, Interfacial microstructure and strength of steel/aluminum alloy joints welded by resistance spot welding with cover plate, Journal of Materials Processing Technology, 209 (2009), 4186-4193 https://doi.org/ 10.1016/j.jmatprotec.2008.11.003

13. W. H. Zhang, X. M. Qiu, D. Q. Sun and L. J. Han, Effects of resistance spot welding parameters on microstructures and mechanical properties of dissimilar material joints of galvanised high strength steel and aluminium alloy, Science and Technology of Welding and Joining, 16 (2011), 153-161 https://doi.org/ 10.1179/1362171810Y.0000000009

14. Z. Ling, Y. Li, Z. Luo, Y. Feng and Z. Wang, Resis tance element welding of 6061 aluminum alloy to uncoated $22 \mathrm{mnmob}$ boron steel, Materials and Manufacturing Processes, 31 (2016), 2174-2180 https://doi.org/ 10.1080/10426914.2016.1151044

15. X. Sun, E. V. Stephens, M. A. Khaleel, H. Shao and M. Kimchi, Resistance spot welding of aluminum alloy to steel with transition material- from process to performance-part 1: experimental study, Welding Journal, 83 (2004), 188S-195S

16. I. Ibrahim, R. Ito, T. Kakiuchi, Y. Uematsu, K. Yun and C. Matsuda, Fatigue behaviour of Al/steel dissimilar resistance spot welds fabricated using $\mathrm{Al}-\mathrm{Mg}$ interlayer, Science and Technology of Welding and Joining, 21 (2016), 223-233 https://doi.org/ 10.1179/1362171815Y.0000000086

17. S. P. Murugan, M. Cheepu, D. G. Nam and Y. D. Park, Weldability and fracture behaviour of low carbon steel/aluminium/stainless steel clad sheet with resistance spot welding, Transactions of Indian Institute of Metals, 70 (2017), 759-768 https://doi.org/ 10.1007/s12666-017-1081-2

18. W. Zhang, Design and Implementation of Software for Resistance Welding Process Simulations, Society of Automotive Engineers, 112 (2003), 105-113 https://doi.org/ 10.4271/2003-01-0978

19. R. Ashiri, M. Shamanian, H. R. Salimijazi, M. A.
Haque, J. H. Bae, C. W. Ji, K. G. Chin and Y. D. Park, Liquid metal embrittlement-free welds of Zn-coated twinning induced plasticity steels, Scripta Materialia, 114 (2016), 41-47

https://doi.org/ 10.1016/j.scriptamat.2015.11.027

20. Y. Zhou, P. Gorman, W. Tan and K. J. Ely, Weldability of thin sheet metals during small-scale resistance spot welding using an alternating-current power supply, Journal of Electronic Materials, 29 (2000), 1090-1099 https://doi.org/ 10.1007/s11664-004-0270-Z

21. S. S. Lim, Y. T. Kim, E. J. Chun, K. S. Nam, Y. W. Park, J. W. Kim, S. Y. Lee, I. D. Choi and Y. D. Park, Effect of Chemical Composition of Nut Material on the Fracture Behavior in Nut Projection Welding of HotStamped Steel Sheet, Journal of Welding and Joining, 34 (2016), 1-10 https://doi.org/10.5781/JWJ.2016.34.2.1

22. V. Vijayan, N. Huda, S. P. Murugan, C. Jeong, S. N. Noh, N. Kang and Y. D. Park, The weldability study of carbon nanotube based 2nd generation primer coated steel for automotive applications, Journal of Mechanical Science and Technology 31 (2017), 4405-4410 https://doi.org/ 10.1007/s12206-017-0840-7

23. H. R. Shahverdi, M. R. Ghomashchi, S. Shabestari and J. Hejazi, Microstructural analysis of interfacial reaction between molten aluminium and solid iron, Journal of Materials Processing Technology 124 (2002), 345-352 https://doi.org/ 10.1016/S0924-0136(02)00225-X

24. S. Kobayashi and T. Yakou, Control of intermetallic compound layers at interface between steel and aluminum by diffusion-treatment, Materials Science and Engineering A 338 (2002), 44-53 https://doi.org/ 10.1016/S0921-5093(02)00053-9

25. P. Marashi, M. Pouranvari, S. Amirabdollahian, A. Abedi and M. Goodarzi, Microstructure and failure behavior of dissimilar resistance spot welds between low carbon galvanized and austenitic stainless steels, Materials Science and Engineering A, 480 (2008), 175180 https://doi.org/ 10.1016/j.msea.2007.07.007

26. M. Pouranvari, A. Abedi, P. Marashi and M. Goodarzi, Effect of expulsion on peak load and energy absorption of low carbon steel resistance spot welds, Science and Technology of Welding and Joining, 13 (2008), 39-43 https://doi.org/ 10.1179/174329307X249342

27. W. F. Savage, E. F. Nippes and R. P. Stanton, Intergranular attack of steel by molten copper depending on the composition, Welding Journal 57 (1978), 9-16

28. A. Munitz, Metastable liquid phase separation in tungsten inert gas and electron beam copper/stainless-steel welds, Journal of Materials Science, 30 (1995), 29012910 https://doi.org/ 10.1007/BF00349662

29. M. Hasebe and T. Nishizawa, Calculation of phase diagrams of the iron-copper and cobalt-copper systems, Calphad 4 (1980), 83-100 https://doi.org/ 10.1016/0364-5916(80)90026-7 